\title{
Problem-Identification Workshop as a Future-Oriented Macroergonomic Tool for Managing the Work Environment
}

\author{
M. A. Sanda ${ }^{1}$, Y. Fältholm ${ }^{1}$, L. Abrahamsson ${ }^{1}$, J. Johansson ${ }^{1}$ \\ ${ }^{1}$ Department of Human Work Sciences, Luleå University of Technology, Luleå, Sweden \\ (email: mohami@1tu.se; ylva.faltholm@1tu.se; lena.abrahamsson@1tu.se; jan.johansson@1tu.se )
}

\begin{abstract}
This paper looks at the challenges that most organizations face in the management of their work environments, with respect to the tools that they can use to effectively capture both the explicit and tacit knowledge held by their employees for subsequent reuse when decisions need to be made. The problem-identification workshop, which is a macroergonomic tool for enhancing the management of work environment in an organization, was tested in an organization. Participants identified organizational problems, proposed solutions to them, realistically assessed the desirability and possibility of these solutions, and finally recommended action plans to the organization for its shortterm, intermediate and long-term design and management of effective work environment towards enhancing work life and productivity in the organization. It was concluded that problem-identification workshop is a good socio-pedagogic method that can be used as an intelligent participatory intervention tool by managers in organizations in the management of their work environments.
\end{abstract}

Keywords - Work environment, problem-identification workshop, participatory ergonomics, macroergonomic tool

\section{INTRODUCTION}

Despite many promising production concepts, organizational models and new technology developed during the last decades, most organizations continue to face a large gap between productivity increase expectations and real implementation of newly developed technologies. This observation has given rise to the thinking that for such gap to be removed, there is the need for the development of holistic knowledge that will help enhance managers' capability of effectively integrating the functionalities of the technical, organizational and human systems of their organizations as well as developing deep specialized knowledge and learning in each area.

It is argued by [1] that the consequence of rapid staff turnover, multi-skilling and a reduced workforce in most organizations is the loss of explicit and tacit business knowledge held by individuals. This knowledge is rarely captured, often difficult to codify and is most commonly transferred through personal experience. Not only is this knowledge difficult to capture, but transferring information and knowledge between disciplines is slow, inefficient and details like contextual information are often unintentionally omitted [1].

Taking into account the fact that today, most organizations (such as those in the deep mine industry) are saddled with numerous work environment management challenges, the question that arises here is; what future oriented methods and/or tools can such organizations use in order to be able to capture both the explicit and tacit knowledge that are held by their employees. Addressing this question will require organizations to adopt a more intelligent and proactive approaches to capturing knowledge for subsequent reuse when decisions need to be made.

The purpose of this paper therefore, is to show the effectiveness of one such future-oriented approach, namely the problem-identification workshop, and the relevance of using it to enhance the management of the work environment in organizations.

\section{Problem Identification Workshop}

The problem-identification workshop is a form of future-oriented workshop [2] which is a very open process and which allow employees who would normally not express themselves at the workplace, but whose insights and concerns on the activities they undertake as well as observe in the organization are a useful resource to managers. In recent years, similar future-oriented methods have been applied to a much wider range of environments including companies, government departments and trade unions [3]. But as [4] observes, these traditional institutions are no longer as influential, respected, or popular as they once were. $\mathrm{He}$ argues that these institutions are gradually becoming uncertain about their current role and future mission, a situation that is making them to rethink what they are and where they are going. The rationale for such rethinking is that many of the organisations that exist today are internally divided and in turmoil, and hence uncertain of what to do [4]. Taking into account this observation, the issue of interest here is to understand the underlying process in carrying out the problem identification workshop.

The problem-identification workshop is a structured process with five defined phases $[5,6,7]$ as listed below.

1) Preparation phase: This phase defines a clear, short and challenging 'theme' for the workshop, acceptable to all participants.

2) Experience phase: This phase highlights all problems (small or large) experienced by participants with regards to the workshop's theme. Participants are made to concentrate on only the "negative" side of the theme with the view that what is good does not need to be changed. 
3) Phantasy phase: This phase is to make participant (employees) come out of the daily limitations that usually lead to restraint, traditional thinking and acting. This is due to the fact that people have many ideas that have never been expressed or formulated because they were framed in what they believe was right and possible. In fantasia, everything is possible. There are no barriers, no economic, personal, technical or organizational limitations. The idea is to develop future visions that had enough power to solve all the critical problems that the group is working with.

4) Strategy phase: In this phase, all the fantasies expressed by the participants are run through with the aim of finding possible barriers that could inhibit the realization of the fantasies. Participants discuss whether any of the barriers could be removed, and if yes, how and when? A programme/plan for the realization of the fantasies decided upon is then prepared.

5) Action phase: A complete report containing all the critical problems, fantasies as well as programmes/plans proposed by the workshop participants are prepared at this phase. This report can then become a future resource for ideas and actions, and an acknowledgement (feedback) for participants to see how hard, intensive and creative they have worked.

According to [5], the practical prerequisite for running a successful problem-identification workshop is a well motivated participating group, a flexible and informal condition as well as two experienced and neutral workshop leaders. Problem-identification workshops have been used to identify various management problems, and to develop vision, ideas and action plan for improvement $[5,7]$.

In this paper, therefore, the workshop that was held in one organization in an African country which experienced challenges in bridging a large gap between productivity increase expectations and real implementation of newly developed business practices to enhance the commercialisation of its activities is highlighted.

\section{METHODOLOGY}

The workshop was conducted under the general theme "the problem with our organization's efforts towards increased productivity". Seventeen employees representing management, senior staff and the junior staff participated. In order to facilitate the application of this technique, a workshop guide entitled "Conduction of Future Workshop: User's Guide for Workshop Leaders" [7] was used as a resource.

At the start of the workshop session, each participant was granted the opportunity to briefly describe a concrete problem that he/she has experienced in the organization. Instead of making the participants' voice out their problem statements, each of them was provided with a set of similar papers and pens (with no colour variation) on which to write their respective problem statements, eliminating the possibility of each statement source being identified by other participants. This made it easier for all the participants to express themselves genuinely and without showing any traces of apprehension by the presence of those in superior positions.

The written statements by each of the participants were re-written exactly and boldly on large sheets of paper until a point was reached whereby no one among the participants had any more critical problems to write out. Thereafter, the participants were made to vote on the listed problems, with each participant being allocated seven votes to be given to the most serious problems, of which two received three votes each and the remaining one receiving only one vote. After calculating the votes, the listed-problems were compiled in ranking order based on their total votes. Following this, critical problems were identified out of which the workshop sub-themes were developed. This was followed by assigning the remainder of the listed-problems to the most appropriate of the four discussion topics. Later, the participants were made to verify whether their expressed problems were listed under the appropriate topic. The discussion topics were then classified as workshop sub-themes which the participants used as platforms to discuss and come out with their solution proposals to the listed-problems. Fig. 1, 2 and 3 below show the three groups at different stages of their deliberations.

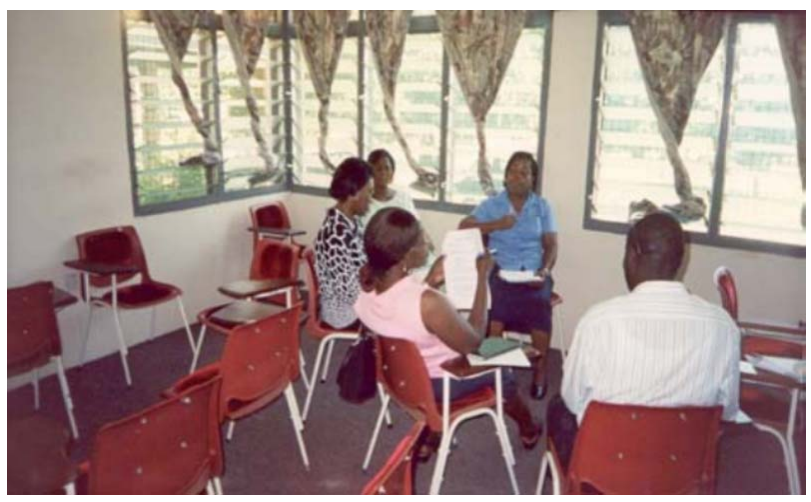

Fig. 1: Group one members discussing their fantasies

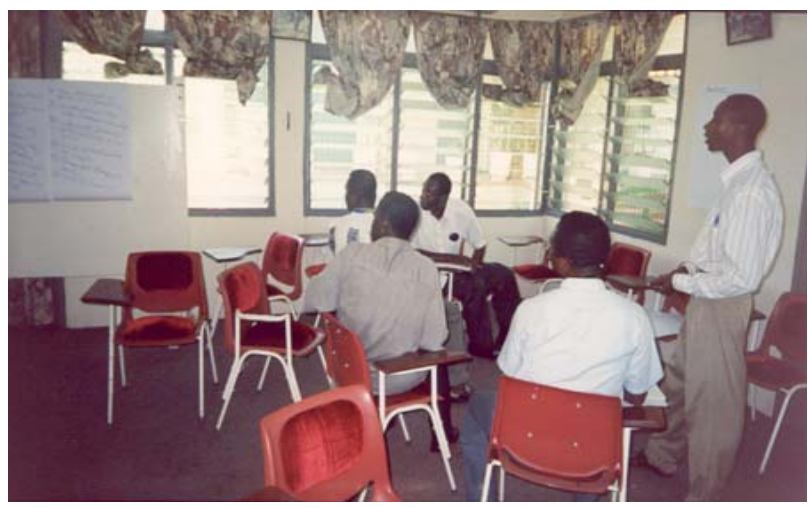

Fig. 2: Group two members assessing the desirability and possibility of their ideas 


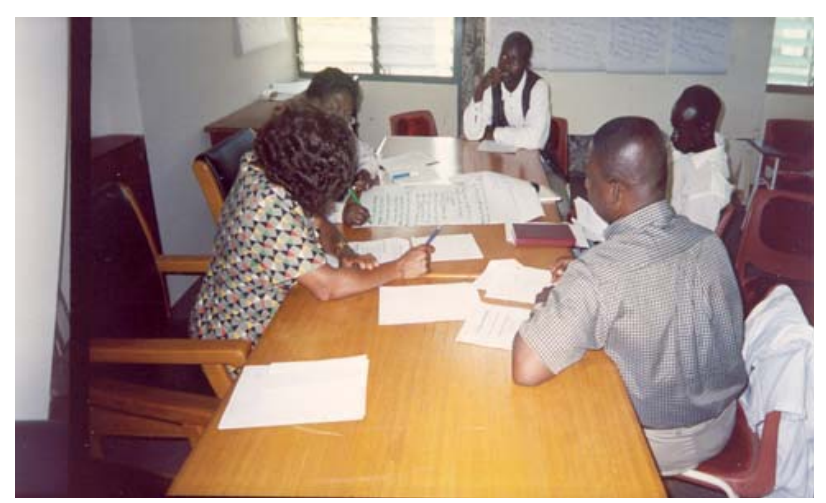

Fig. 3: Group three members preparing their action plan

Participants in each group phantasied the best solutions to help overcome the problems and/or constraints identified with their respective sub-themes. Participants came out of the daily limitations which usually lead to restraints, traditional thinking, and acting. As a result, many new ideas that the participants had in their unconsciousness popped up after thinking over their daily limitations. Everything was considered possible in this phase (i.e. no cultural barriers, and also no economic, personal, technical, and organizational limitations).

For each group, each member's fantasy was discussed with regards to its ability to solve one or more of the problems associated with the group's specific theme. Disagreement within the group was allowed and accepted. The phantasies developed by each group for specific subtheme were listed. Participants then conducted a Desirability (D) and Possibility (P) assessment of their various alternate solutions which allows for the practical choice of the most feasible.

A workshop report (one day after the workshop) detailing the entire proceeding (i.e. from the listedproblems to the solution proposals) was prepared and presented to the management of the organization with copies to each workshop participant for comments and verification.

\section{RESULTS}

In the problem identification phase, a catalogue of forty-one (41) problems/constraints as expressed by the participants was developed. After the voting process, the following 7 problems and/or constraints were deemed to be critical to the organization.

- Staff attitude.

- Demotivation of staff.

- Commercialisation concept not well understood.

- Lack of funds.

- Lack of training.

- Management commitment.

- Marketing not aggressive.
Using the above-listed critical problems and/or constraints as guide, the participants developed the following three sub-themes for the workshop:

- Reorientation of staff attitudes towards the work.

- Lack of management commitment towards staff need (with emphasis on training, funding, and staff demotivation).

- Marketing strategy.

The solutions (i.e. future visions) that were perceived to have enough power to solve all the critical problems and/or constraints identified under each of the three subthemes above, and the participants' assessment of the Desirability (D) and Possibility (P) of each solution are outlined below. The desirability and possibility assessment was to allow for the practical choice of the most feasible solutions.

\section{Solutions towards Reorienting Staff Attitudes to Work}

1. Train staff on work ethics. $[\mathrm{D}=100 \% ; \mathrm{P}=90 \%]$

2. Develop flowchart to show the inter-dependence of grades of staff and units. [D=90\%; $\mathrm{P}=80 \%$ ]

3. Indiscipline among the staff should not be tolerated, and offenders should be sanctioned. $[\mathrm{D}=80 \%$; $\mathrm{P}=70 \%$ ]

4. Institute best worker and discipline awards. $[\mathrm{D}=80 \%$; $\mathrm{P}=80 \%$ ]

5. Motivate staff with long service awards (example, 10 years and above). $[\mathrm{D}=100 \% ; \mathrm{P}=80 \%$ ]

6. Senior members must set good examples, in terms of discipline and hard work. [D=90\%; $\mathrm{P}=90 \%]$

7. Improve security and the environment (uniforms, record-keeping of visitors, landscaping of the environment). $[\mathrm{D}=100 \% ; \mathrm{P}=60 \%]$

8. Every staff to sign attendance book (both "in" and "out"). [D=80\%; $\mathrm{P}=80 \%]$

9. Proper arrangement should be made before staff is recruited (such as office accommodation and job description). Such new staff should go through orientation and counseling from time to time. $[\mathrm{D}=80 \% ; \mathrm{P}=70 \%]$

10. Supervision should be improved at all levels. $[\mathrm{D}=100 \% ; \mathrm{P}=100 \%]$

Solutions for Overcoming Management's Lack of Commitment towards Organizational Goals

1. Management should have a programme for training of staff and must implement it. [D=100\%; $\mathrm{P}=80 \%$ ]

2. Training needs of staff should be identified on periodic basis (yearly). [ $\mathrm{D}=100 \% ; \mathrm{P}=100 \%]$

3. Funds should be sourced and prioritised. $[\mathrm{D}=1000 \%$; $\mathrm{P}=80 \%]$

4. Staff should be motivated by level of work done. $[\mathrm{D}=70 \% ; \mathrm{P}=50 \%]$ 
Solutions for Improving Organization's Marketing Strategy

1. Serious conscientization of top management and staff in marketing. [D=90\%; $\mathrm{P}=90 \%$ ]

2. Staff periodic orientation in marketing. $[\mathrm{D}=90 \%$; $\mathrm{P}=90 \%]$

3. Research must address the marketing concept. $[\mathrm{D}=90 \% ; \mathrm{P}=40 \%$ ]

4. Organization must embark on aggressive promotional activity. [D=90\%; $\mathrm{P}=60 \%]$

5. Identify products with competitive advantage. $[\mathrm{D}=90 \% ; \mathrm{P}=50 \%]$

6. Identify potential clients $[\mathrm{D}=90 \% ; \mathrm{P}=60 \%$ ]

7. Develop strong linkages between organization and industries. [ $\mathrm{D}=90 \% ; \mathrm{P}=80 \%$ ]

8. Set achievable targets. $[\mathrm{D}=90 \% ; \mathrm{P}=55 \%]$

9. Establish good customer relationship. [D=90\%; $\mathrm{P}=70 \%$ ]

10. Reward for exceptional performance or contribution. $[\mathrm{D}=90 \% ; \mathrm{P}=50 \%]$

11. Just-in-time delivery to clients. $[\mathrm{D}=90 \% ; \mathrm{P}=70 \%]$

\section{Proposed Plan of Action Recommended To Management}

Based on the desirability and possibility assessment highlighted above, and taking into consideration factors such as Economic, Technical, Organizational as well as existing organizational and societal Realities, the following strategies for change were developed.

1) Plan for reorienting staff attitudes towards work: The following actions were proposed as the required steps necessary for training staff on work ethics.

- Divisional or Unit "open" forum for informal discussion (at least once a quarter).

- Making use of communication skills and interactions with subordinates.

- Institution of socialization activities at Unit/Division level.

- Staff should be made familiar with conditions of service at all levels.

- Institute channels for complaints (e.g. suggestion box).

- Supervision at all levels should be encouraged to set good examples.

2) Plan for overcoming perceived management's lack of commitment to organizational goals. The following actions were proposed for removing the existing barriers in the organization.

- Good business plan to convince funding agencies.

- Timely delivery as well as attitudinal change.

- Prices of goods and services must be affordable.

- Proper auditing.

- Better planning for the provision of inputs (i.e. advance and timely preparation of estimates).

- Better remuneration.

- Monthly review of commercial activities.

- Constant monitoring of daily activities.
- Penalizing staff for non-conformity.

3) Plan for improving organization's marketing style: The following actions were proposed for developing stronger link between the organization and stakeholders in industries.

- Sustain already existing clients.

- Win 10 new clients annually.

- Increase revenue by $70 \%$.

- Visit to key clients twice every year to discuss organization's services provision to them.

- Invitation of key clients to organization's “end of year" get-together.

- Visit to industries to prospect for clients.

- Participating at trade fairs and exhibition.

- Provision of updated brochures.

All the above results were put together into a workshop report that was discussed with the managing director of the organization, and this resulted in the taking of remedial actions on some of the problems identified at the workshop and for which feasible solutions were proposed by the participants.

\section{DISCUSSION}

The result above has shown that an organization is a social structure wherein employees can play a decisive role in improving its performance. Even though organizational change is known to be a difficult, time consuming, and expensive process, the creation of a participatory platform will bring to the fore a good understanding of cultural factors in organizations, including the way people interact with each other and commit themselves to organizational goals. The implication here is that management can develop a good understanding of their work environment and be able to enhance increased productivity as well as improve the quality of work life in their organizations by matching management methods and techniques to the organizational aspirations of their employees.

This is because, as increased competition in global markets continues to impose higher challenges on innovation, productivity, and product quality, organizations also have to respond by having a knowledgeable workforce with broader skills who are flexible and motivated to share their knowledge with their management. To achieve this, an organizational structure and management system is required in which operators' knowledge and skill are continuously improved through education and training and the total company resources are fully utilized for optimum performance and for dealing with rapidly changing problems at work [8]. In this endeavor, by regarding employees as central to all their development initiatives, organizations can derive much benefit from their knowledge. As [9] argues, skills and knowledge should not be seen as things that are simply static and accumulated by individuals, but rather as things that are created and changed in socio-cultural contexts, 
through individual as well as collective processes. The implication being that knowledge is not only a question of individual behaviour, but also about organization, power and identity [10].

Because the introduction of new technology needs to be legitimized by the workers as well as by management, a number of studies have emphasized the significance of worker participation in the introduction process $[11,12]$. According to [13], effective participatory ergonomics program can take many forms. In this regard, the best program for any organization in any culture may depend on its own unique history, structure and culture. The problem-identification workshop is thus a useful macroergonomic approach that can help organizations develop their best and unique programs that they can use to enhance the management of their work environments towards increased productivity.

\section{CONCLUSION}

Based on the discussion above, it could be said that the problem-identification workshop is good method for identifying organizational problems and developing feasible and acceptable solutions for improvement. It also created a platform that enhances cooperation between managers and employees in a participatory problemsolving process. It is a socio-pedagogic method for the identification of a common problem, development of a vision, ideas and action plan among a group of people concerned. The technique can be used as a participatory intervention method by managers in organizations. It can also be used as a good qualitative instrument for decisionmaking and work environment analysis.

\section{REFERENCES}

[1] J. Bassan, V. Srinivasan, P. Knights, and C. T. Farrelly, (2008). A day in the life of a mine worker in 2025, in Proc. 1st International Future Mining Conference, 2008, Sydney, NSW, p. $71-78$.

[2] R. Jungk and N. Mullert, Future workshops. How to Create Desirable Futures. London: Institute for Social Inventions, 1987.

[3] Strategic Futures Team, A Futurist's Toolbox: Methodologies in Future Work. Cabinet Office, Denmark: Performance and Innovation Unit, 2001.

[4] J. C. Glenn, J. Dator, and T J. Gordon, "Closing the deal: how to make organizations act on futures research", Foresight, vol. 3, no. 3, pp. 177-189, 2001.

[5] F. Helali and H. Shahnavaz, "Adapting macroergonomic approach for identification of workplace problems and development of low-cost/no- cost solutions in industrially developing countries. Case study: Glucosan - Iran", in Human Factors in Organizational Design and Management - VI, P. Vink, E. A. P. Koningsveld, and S. Dhondt, Eds. Amsterdam: North-Holland, 1998, pp. 585-590.

[6] I. Skoglind-Öhman, and H. Shahnavaz, "Assessment of future workshop's usefulness as an ergonomics tool",
International Journal of Occupational Safety and Ergonomics, vol. 10, no. 2: 119-128, 2004.

[7] M. A. Sanda, Four Case Studies on the Commercialization of Government R\&D Agencies: An Organizational Activity Theoretical Approach. Doctoral Thesis. Luleå, Sweden: Luleå University of Technology Press, 2006.

[8] H. Shahnavaz, "Macroergonomic considerations in technology transfer", in Macroergonomics: Theory, Methods and Applications, H. W. Hendrick and B. M. Kleiner, Eds. New Jersey: Lawrence Erlbaum, 2002, ch. 15, pp. 311-322.

[9] L. Abrahamsson, and J. Johansson, "Future Mining Workers' Skills, Identity and Gender When Meeting Changing Technology", in Proc. 1st International Future Mining Conference, 2008, Sydney, NSW, p. $213-220$.

[10] T. Fenwick, "Learning as grounding and flying: Knowledge, skill and transformation in changing work contexts", presented at the From Grounded Skills to Sky Qualifications Conference, Kiruna, Sweden, 2005.

[11] K. Noro, and A. Imada, Participatory Ergonomics. London: Taylor \& Francis, 1991.

[12] J. R. Wilson, "Participation - a framework and foundation for ergonomics" Journal of occupational psychology, vol. 64, pp. 67-80, 1991.

[13] J. K. Liker, M. Nagamachi, and Y. R. Liftshitz, "A comparative analysis of participatory program in U.S and Japan manufacturing plants", International Journal of Industrial Ergonomics, vol. 3: 185-199, 1989. 